\title{
Striped effects: \\ The articulation of materiality and directionality in striped architecture
}

\author{
Ashley Paine
}

\section{Introduction}

The striped interior of Siena Cathedral is often described as a wondrous experience: the intensity of its black and white surfaces striking the viewer as both dazzling and disorienting (Fig. 1). It is also a remarkable demonstration of the psycho-perceptual effects of stripes, and their capacity to assert the physical and visual qualities of space in a dialectical interplay that oscillates between materiality and immateriality. This is to say that the banding of light and dark stone draws particular attention to the physical qualities of the building material - its thickness, mass and, above all, its colour - as well as the construction technique of stone blocks laid one upon another. At the same time, the incessant repetition of stripes highlights the interior as a visual surface, and brings into one's consciousness an experience of the space as a shimmering field of optical sensation, perspectival tricks and immaterial effects - effects that are quite distinct from the physical qualities of the masonry wall. Of course, any striped pattern can be thought of in such dualistic terms: both as a physical organisation of matter into banded chromatic oppositions, and as an optical structure independent of a physical support. While this paper is not about Siena's remarkable cathedral, its dramatic interior opens up a broader discussion on the articulation of architecture using the material and immaterial effects of stripes.

The spectacular display of interlinear colour at Siena Cathedral is but one particularly intense example from a long history of striped masonry architecture. Many others exist. ${ }^{1}$ The earliest known are Roman constructions dating from the first century BC. These structures employed a technique known as opus vittatum in which walls were built with a facing of banded brick and stone, ostensibly for constructional and decorative purposes. It was from this ancient practice that stripes emerged, forming what is arguably one of the oldest and most enduring methods of ornament in occidental architecture. Remarkably, stripes continue to be used today, although they are most commonly associated with only a small selection of historical works: the medieval churches of northern and central Italy (such as Siena); the polychrome brickwork of the High Victorian Movement; Loos' unbuilt Josephine Baker House; and the work of certain Post-Modernists including, most notably, Swiss architect Mario Botta.

Despite their frequent occurrence and visual impact, the presence and significance of stripes have been largely overlooked by architectural historians and theorists. And, while there are some reasonably consistent formal typologies that may be identified in the tradition of horizontally striped buildings, it is difficult to attribute any stable meaning or intent to them over the past 2000 years. This paper takes a synchronic approach to the striped building canon, and focuses on Mario Botta's Watari-um Museum of Contemporary Art in Tokyo (1985-1990) as its main object of discussion. While the building has been widely published, its stripes typically attract only passing mention. ${ }^{2}$ Elsewhere, I have begun to address this gap in the discourse, arguing that Botta's use of stripes reveals certain Post-Modern 
tendencies and a latent historicism in his work which contradicts the architect's ostensibly modernist agenda (Paine 2012). For the present discussion, the Watarium's façade highlights a series of significant issues regarding the effects of stripes applied to architecture. But there is another more fundamental problem for this paper. While we can observe their spatio-visual effects, we do not have the conceptual tools or critical discourse with which to examine striped building surfaces in a meaningful way. Here, some of the early writings of Rosalind Krauss will be used to begin to unpack the perceptual effects of striped architecture, beyond a merely intuitive response to their spatio-visual phenomena.

The ambitions of this paper are three-fold. First, to examine the perceptual effects produced by the interaction of stripes and architectural form; second, to consider their perceptual effects in their interaction with architecture and space; finally and perhaps most importantly, to draw upon visual art theory to establish a conceptual groundwork and discursive vocabulary with which to describe the formal, material and visual effects of striped buildings. Hence, by bringing together Botta's Watari-um and Krauss' texts, the paper attempts to redress the use of stripes in architecture, and provide the means through which we may examine their effects on form, space and the viewer. It also enables a discussion on the significance of these striped effects within a broader contemporary discourse on the architectural surface. We must begin, however, by establishing a more general understanding of the visual function of stripes.

Fig. 1 Siena Cathedral (thirteenth century). [Interior. Photo: Author, 2012]

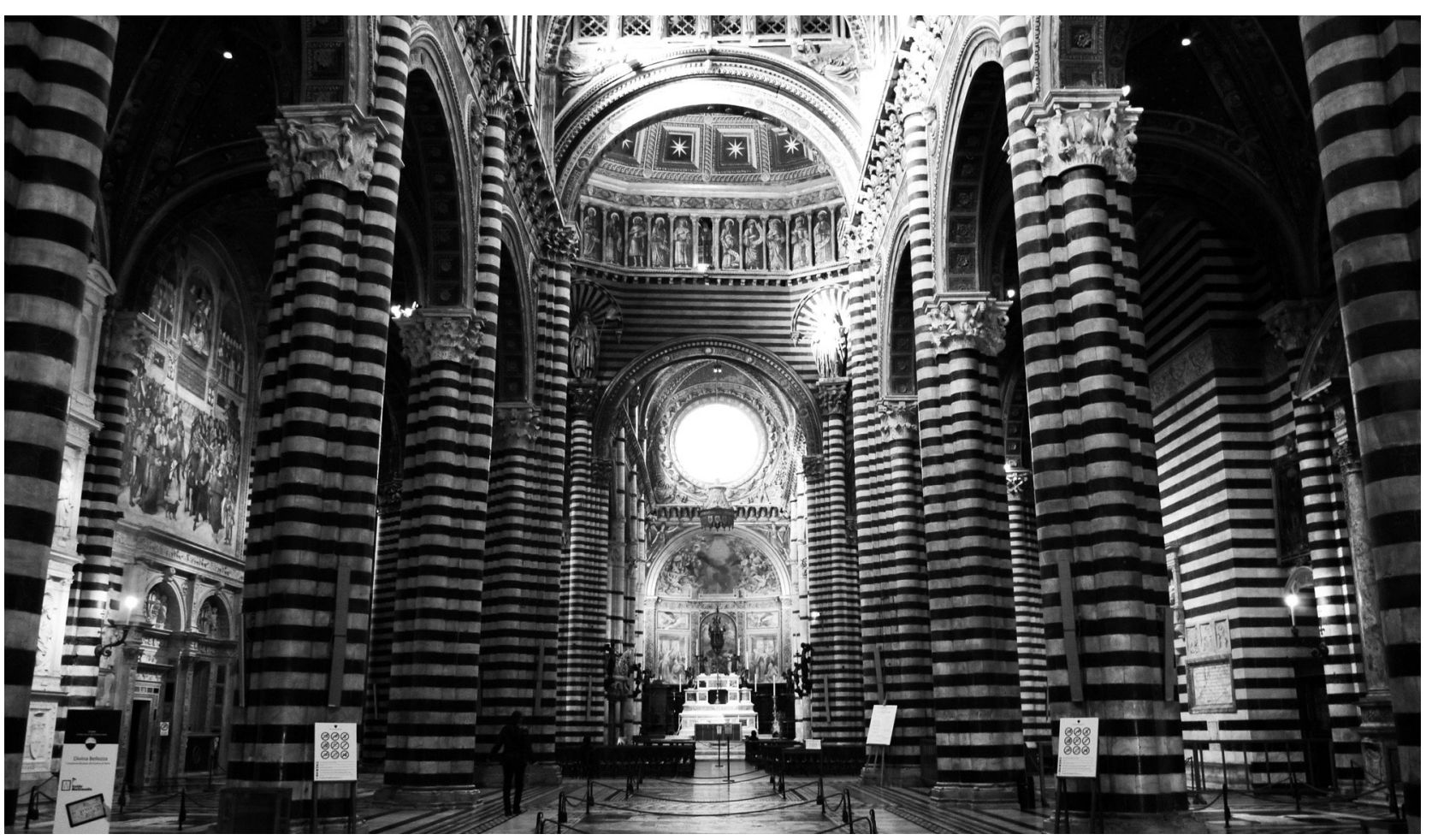


Fundamentally, stripes are conspicuous. They draw attention to themselves, and lead the viewer's eyes across a given surface. This salience brings with it a capacity to affect the perception of both form and space, enabling stripes to reveal, to highlight and to amplify those things to which they attract our eye. At the same time, this can also be an act of concealment, as stripes obscure that from which our attention is taken. ${ }^{3}$ Such illusory properties are also popularly understood. For example, the patterning of a zebra, or the "dazzle painting" on some World War I battleships, demonstrate the camouflaging, or confusion-producing, effect of stripes.

Similarly, illusions such as the Helmholtz Square are well known, and explain how horizontal and vertical stripes can cause an overestimation of a figure's height or width respectively. Figure 2 demonstrates the illusion: A appears taller than B, even though both conform to a square figure of identical size.

Fig. 2 Helmholtz Square Illusion. [Drawn by author, after Helmholtz (1925: 193)]
Fig. 3 Striped Square Figures. [Drawn by author, adapted from van Pelt (1902: 139)]
3 Michel Pastoureau comes to similar conclusions in his history of striped textiles (2003: 91).

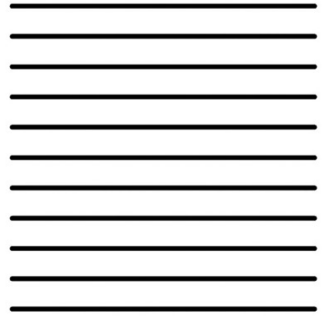

A

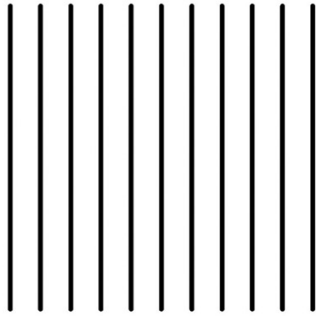

B
However, such effects can be undermined, even reversed, depending on how they are used. As John Vredenburgh van Pelt points out, the efficacy of the Helmholtz Square illusion, for example, depends on the arrangement of stripes in relation to one's reading of the overall figure that bounds the pattern (1902: 140). This might explain why, contrary to the Helmholtz principle, vertical rather than horizontal stripes are commonly used to make a small room appear taller. Figure 3 demonstrates van Pelt's idea, and shows how stripes that are indifferent to their support's boundaries (here shown dashed) can form a new and independent figure with its own horizontal or vertical bias. Indeed, this consonance or dissonance between the support and the striped figure appears to lie at the heart of the clarity or confusion-inducing effects of stripes.

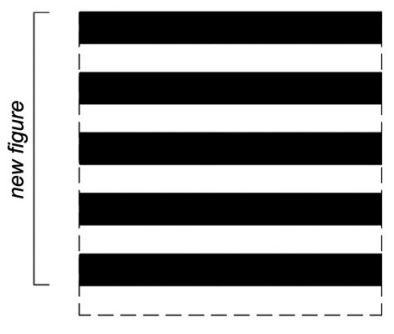

A

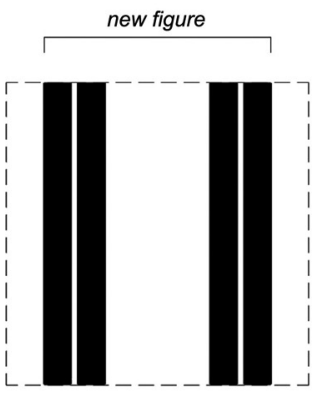

B
Most of these effects, however, deal only with stripes on isolated, two-dimensional surfaces, and seem to demonstrate the same thing: the inherent capacity of stripes to demand our attention or deceive our eyes. On three-dimensional surfaces, the effects of stripes become more uncertain, demonstrated by the continuing popular 
conjecture on the 'slimming' effect of striped clothing. Applied to architecture, stripes can interact with two-dimensional surfaces and three-dimensional forms in even more complex ways, and are perceived dynamically by a moving observer. It is in this context that the paper will now focus on the production of frontality and rotation. These are two significant spatial conditions that are brought to the fore by striped building surfaces. They are also two important concepts that help us to understand the visual behaviour of stripes, and to describe their material and immaterial effects on the perception of architecture.

\section{Botta's Watari-um and the assertion of frontality and rotation}

Ostensibly, stripes can enhance the expression of frontality in a given building simply by asserting the planarity of the façade. This is evident in the Watari-um - Botta's first museum project - where the stripes provide a visual register of the flatness of the building surface (Fig. 4). Located on a tiny triangular site of just $157 \mathrm{~m}^{2}$, the Watari-um's five above-ground storeys face a busy street in Tokyo's Shibuya district with a flat pre-cast concrete façade, striped with inlaid bands of black granite. While Botta has repeatedly used stripes to secure the frontal primacy of his projects, the combination of pale concrete and dark stone on the Watari-um marks it as a particularly bold example. Indeed, the façade appears imposing, monumental, and much taller than its actual number of floors. Harald Szeemann describes the building's surprising grandeur as a "magic act" that has transformed its small urban site with the building exhibiting an almost sacred presence (1990: 37-8).

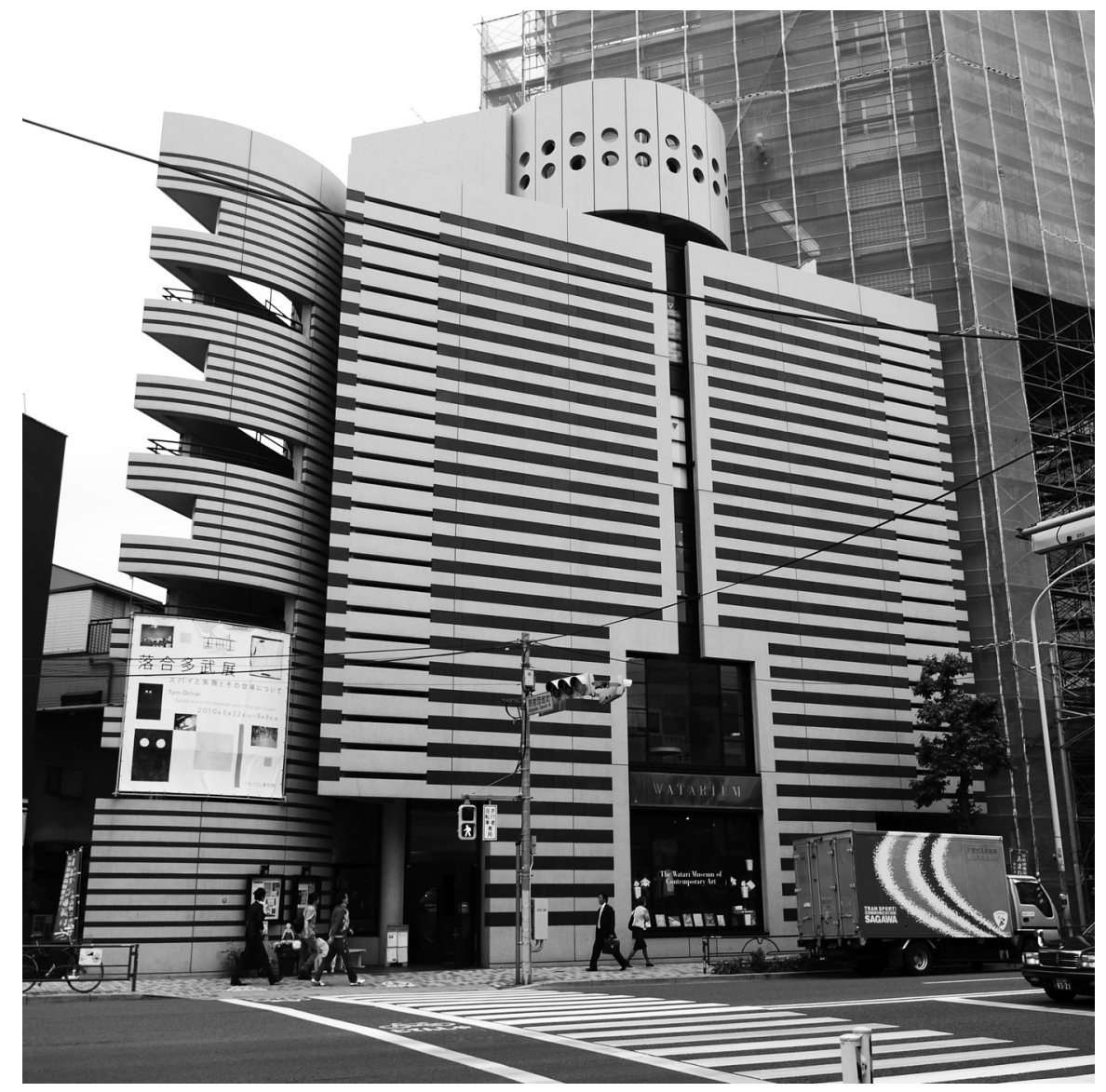

Fig. 4 Mario Botta (1985-1990). Watarium Museum of Contemporary Art Tokyo [Street view. Photo: Author, 2010] 
This paper contends that the visual impact of the Watari-um emerges as a direct result of its stripes, which enhance the severely frontal composition through their consonance with the figure of the façade, and form an almost perfect reproduction of the Helmholtz Square. Indeed, such an emphatic declaration of the façade seems to have been Botta's intention. Beginning in October 1985, he spent some five years and 20 iterations to achieve his final design (Pizzi 1998: 3) - the stripes appearing as early as the second scheme (Watari 1990). Writing to his client, Ms Shizuko Watari, upon the completion of the museum, Botta notes that:

from the first drawings on I followed a strong and precise sign that had to resist the confusion and the contradiction of languages, styles and forms present in Tokyo ... the main front is axial and stretched for its maximum frontal extension (as if it were the search of a maximum wing span for a bird). (Botta 1990: 8-9)

At the Watari-um, the use of frontality and stripes appears to be an assertion of strength and an exaggeration of scale, deployed to simultaneously confront and resist the building's context: the façade faces the street head-on, and provides a mask to the internal workings and organisation of the gallery. It even conceals the reading of individual floors, further complicating the perception of the building's scale. However, Botta's gallery is also of interest because of its three-dimensional rotation. This is discernible on the gently curved fire stair located to one side of the main façade, where thinner bands of black granite form an index of the contoured building surface, and differentiate the stair as an independent compositional element. Here the stripes exaggerate a sense of phenomenal rotation and movement through their emphasis on curvature, obliqueness and spatial depth. This rotational condition is distinctly less aggressive than the frontality of the façade: it is subdued by the reduced scale of the stripes, but also by their inherent denial of any possible frontal view. What is important in the Watari-um's use of stripes is that they clearly demonstrate the way in which banded ornament can draw attention to both the two- and three-dimensional conditions of the architectural form. Yet this is not simply a matter of the flat as opposed to the round. The concept and experience of frontality and rotation each imply much more complex spatio-visual conditions that require closer examination.

\section{Frontality and rotation: concept and experience}

The oppositional pairing of the terms "frontality" and "rotation" appears to be have been first used by art theorist and critic, Rosalind Krauss, in her essay "Leger, Le Corbusier, and Purism" from 1972, although she tackled the same issues in the 1968 essay "On Frontality", where she contrasts the notion of frontality with the concept of the oblique. While neither text is about stripes, she illustrates the earlier text almost exclusively with images of striped paintings, including works by Kenneth Noland and Frank Stella composed variously of stripes, banded arcs and chevrons. While this engagement with stripes appears incidental, Krauss' writings remain central to this paper for their examination and theorisation of the spatial and phenomenological effects of frontality and rotation.

It should be noted that the concepts of frontality and rotation have also been paired by other key twentieth-century architectural writers and theorists. For example, Kenneth Frampton used the terms in his essay "Frontality and Rotation" from 1975, to describe the shared compositional techniques of the New York Five. In his later discussion of works by Michelangelo and Le Corbusier, Colin Rowe made use of the concepts in much the same way but replaced "rotation" with the 
term "contrapposto" (1996). The point is that the attention given to these ideas by Frampton and Rowe, and their use by such important figures in architectural history, highlights the broader significance of frontality and rotation for the practice of architecture, despite being largely ignored in contemporary practice, and never before addressed in relation to stripes.

There are parallels that can also be drawn with other discourses on perception. These include Heinrich Wölfflin's much earlier formal division of the "linear" and "painterly" - terms which parallel key aspects of Krauss' "frontality" and "rotation" respectively - in his Principles of Art History (1932). Indeed, we can borrow from Wölfflin's text to help characterise some of the formal and spatial qualities of these two terms, as well as their fundamental distinction between the concept and the experience of the two- and three-dimensional conditions of form. To summarise, the idea of frontality ("linear") emerges not simply as a two-dimensional condition, but implies a frontal two-dimensional representation of a three-dimensional form that, like an architectural elevation, enables a precise understanding of the object, is dimensionally accurate, and as we know it to be. By contrast, the concept of rotation ("painterly") suggests a more contingent point of view that more like a perspective drawing - provides a visual semblance to the object, which is less precise, less defined, but true to how we actually see it (Wölfflin 1932).

While Wölfflin maintains a strict separation between architecture conceived in a linear or painterly mode, it is interesting to note that Krauss, Frampton and Rowe each recognise the interplay of frontality and rotation within a single work of architecture. And, despite some differences, all three acknowledge the important, formative co-existence of frontality and rotation in the works of Le Corbusier. We will return to the significance of their juxtaposition in the case of the Watari-um, but for the moment, Krauss' writings, which link stripes to frontality and rotation, demand more detailed consideration.

\section{Stripes, frontality and rotation}

Of all the writers who have described the conditions of frontality and rotation, it is only Krauss who-specifically in her description of a few banded paintings of the 1960 s - provides a connection to stripes. In the essay "On Frontality”, Krauss points out that the assertion of frontality is assisted by the use of certain types of symmetry. In particular she compares the early striped chevron paintings of Noland, which employed vertically symmetrical triangular forms, to his later works that used similarly striped forms but with a horizontal plane of symmetry. Regarding the earlier paintings, Krauss says that the balance of the left and right hand sides reinforces the latent frontality of the image, whereas the left-right imbalance of the later works undermines it. She writes:

Now turned sideways, the chevrons act to pivot the canvas so that the physical distance between the viewer and the right and left points of the picture's edge appears unequal. The uncertainty about the painting's shape which this illusion provokes seems to be a function of the horizontal axis itself. (1968: 45-46)

In other words, the difference between the left and right hand sides of the painting means that we can never confirm that we are looking at the picture front-on, and the ambiguity of this view introduces a sense of movement, or rotation, towards and away from the viewer, destabilising the picture's frontality. Admittedly, the 
use of stripes in these pictures is not critical to the effects, but they do play a part in establishing and asserting the symmetry of the works. More importantly, the geometric regularity of the stripes enables us to see these symmetries more clearly; it draws attention to them, obliging the viewer to recognise the frontality of the early pictures, or its denial in the later ones.

Further observations on the nature of frontality and rotation are developed in Krauss' discussion of architecture. Regarding Le Corbusier's Villa Roche, Krauss describes the movement through the house as a careful combination of both prospect and promenade: concepts that she equates with frontality and rotation respectively. Krauss writes:

Le Corbusier insists upon the rigid frontality of all objects experienced from a distance, and further, that frontality and distance combine to allow knowledge of the real only by inference. Against this he pits the separate kind of knowledge one can have of proximate space by means of rotation through it. So that, for Le Corbusier, the counterpoint between frontality and rotation equals the contrast between ideation and experience. (1972: 52)

For Krauss, this ideational nature of frontality in architecture is much like the pictorial space of a painting: it establishes an illusionistic depth that cannot be entered physically. Rotation, on the other hand, is connected with spatial experience, corporeal perception and movement. Likewise, in painting, Krauss identifies an opposition between the illusory spatial depth of a frontal view - whether the literal depiction of space or a phenomenal sense of depth in abstract works - with the material fact of a painting's literal surface. Whereas a frontal view provides access to a fictive space, the actual materiality of the painting as a thing-in-space is more readily recognised from an oblique perspective (see Krauss 1968: 42). Hence, to "see" into the spatial illusion of the picture, the viewer must defeat the perception of a painting as a three-dimensional object and, instead, identify with its frontality.

But striped building surfaces do not have an illusionistic depth in the sense Krauss describes. If we are to maintain the idea that stripes do indeed help to establish frontality, we must also question its correlation with distance and imagistic space. Thomas Puttfarken's more recent text on pictorial composition offers an alternative way to think through these issues (2000: 1-42). In particular, he critiques concepts of frontality that emerge (like Krauss') from an understanding of pictures as if they were a distant scene viewed through an open window. While such scenes may take on picture-like qualities, Puttfarken argues that the frontality of images on two-dimensional surfaces emerge from very different conditions. In short, he suggests that a picture's frontality is achieved not through the perception of distance, but rather, through a fixed relationship between the elements of the picture and the picture plane itself. Unlike a scene viewed through a window, this conception of surface-bound frontality is stable: it is neither lost nor changed as we move about in relation to the image (Puttfarken 2000: 20-30). Indeed, Puttfarken likens this correlation between an image and its surface to a "façade" (24). We might therefore conclude that while distance might offer a sense, or semblance, of frontality, it is not ultimately dependent upon distance as Krauss seems to suggest. This point is important to the current discussion because it reveals that the frontality of striped architectural surfaces might be similarly constructed through the correlation of stripes with the plane of the building façade. 
Thus frontality can be achieved not only by highlighting the planarity of a surface, but also by establishing certain symmetries, obscuring the perception of materiality, and by establishing a consonance between stripes and the building surface. Returning to Botta's Watari-um as an example (Fig. 4), the eye is attracted to the stripes which, like Noland's chevron paintings, help to establish an ideal position in front of the façade where the viewer's plane of vision is parallel to the plane of the building. From this position, the distortions of perspective are minimised and the elevation is made symmetrical and precise. Moreover, the graphic quality of the stripes draws attention to the two-dimensional figure of the building, and distracts attention from the materiality of the surface - it is not immediately apparent that the black stripes of the façade are composed not only of inlaid panels of dark granite, but also incorporate the shadowed voids of deeply recessed windows (Fig. 5). Such details become insignificant, and the Watari-um's layers of concrete and black stone are transformed into a two-dimensional surficial construction.

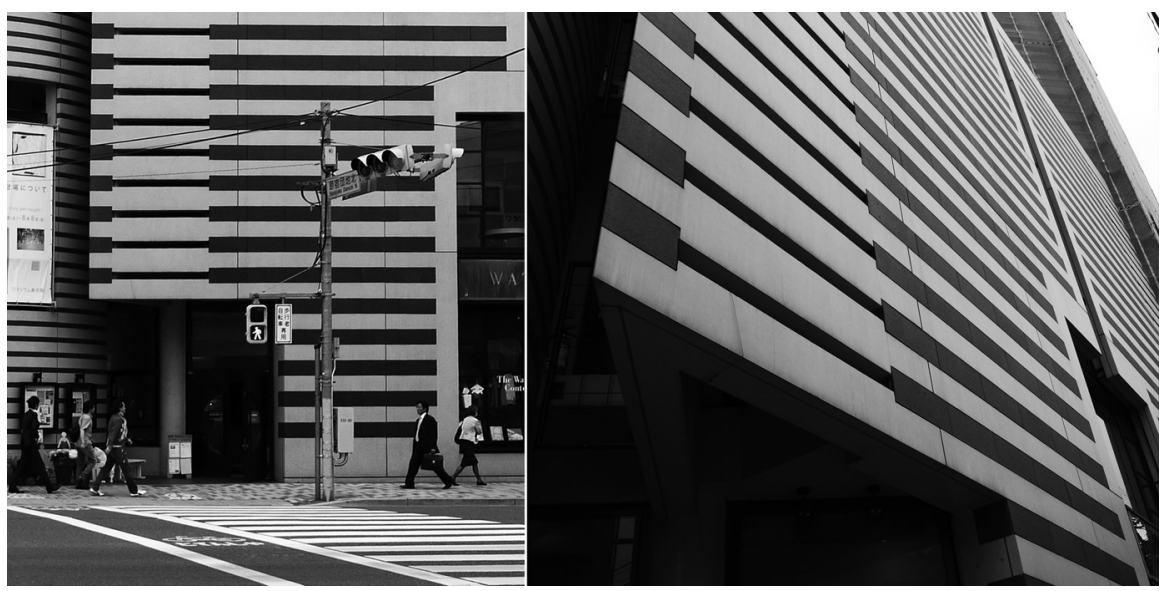

Moreover, while frontality is not dependent on physical distance from the building surface, Krauss helps us to recognise that frontality still has a distancing "effect" at the Watari-um. It produces an ideational separation that excludes the viewer, and encourages the striped façade to be perceived at a remove. Indeed, Botta appears to be conscious of these effects of his stripes. In a recent interview with the author he confirmed that he uses stripes to stress "the monumentality of the elevation. In the case of the Watari-um in Tokyo, the dark stripes ... enlarge the dimensions of a small building with respect to the surrounding fabric" (Botta 2012). In short, the Watari-um façade is intended to be an impressive sight, not an intimate experience.

The converse is true when stripes are used to amplify the rotational qualities of a given space. As it has already been argued, stripes can highlight the contour of a surface. But, stripes can also confuse the reading of the form. As Krauss suggests, this ambiguity draws us closer in, and encourages us to move around the object, and to recognise its materiality and physical mass. In the case of the Watari-um, the striped stair curves away from the observer, and literally leads visitors in to the building entrance. However, at Siena Cathedral, the stripes all but obliterate the architectural form. Its stripes even overwhelm the strong axial plan by demanding the viewer's constant attention on oblique and tangential views: the appearance of the interior shifts and changes with every movement of the observer (Fig. 6). The richness and complexity of these fleeting images encourages the viewer to keep
Fig. 5 Mario Botta (1985-1990). Watarium Museum of Contemporary Art, Tokyo [Street view detail (left) and façade detail (right). Photos: Author, 2010] 
Fig. 6 Siena Cathedral (thirteenth century) [Interior detail. Photo: Author, 2012] moving through the space to explore its optical possibilities. Here, the capacity of stripes to assert the rotational qualities of space is most clearly illustrated - they emphasise the visual and sensual experience of form, at the expense of the clarity of that form - in stark contrast to the Watari-um's overt assertion of frontality.

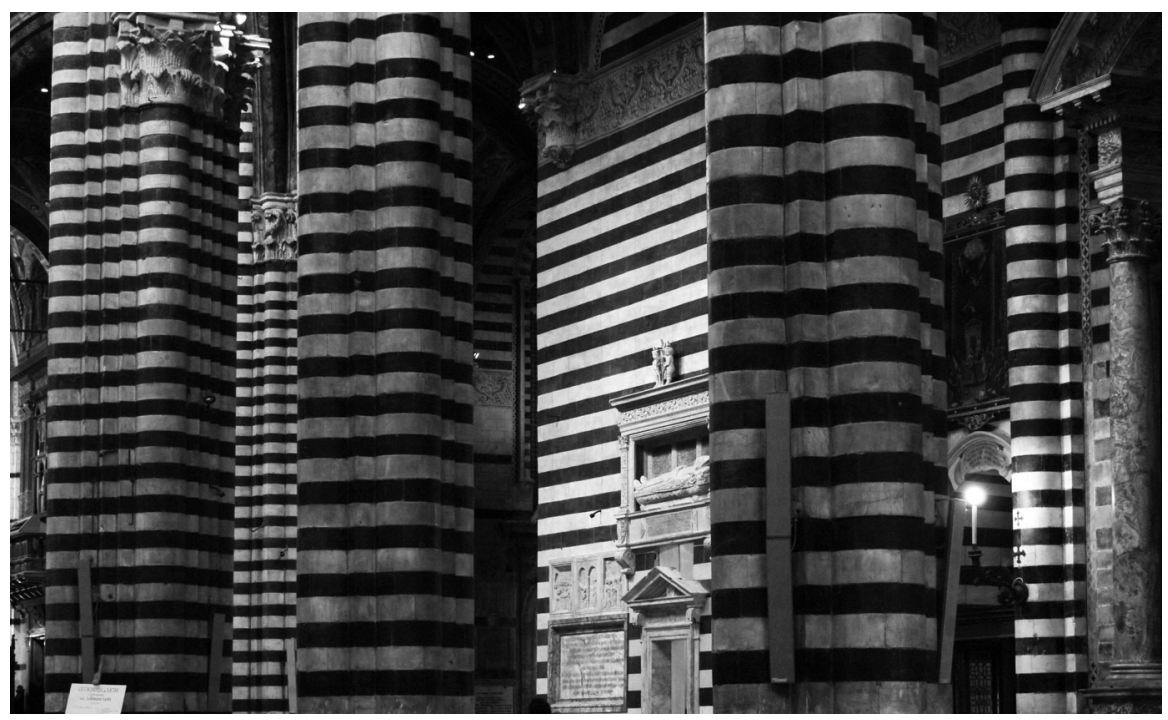

In this light, frontality and rotation are not simply another pair of visual effects of stripes that operate through clarifying or obscuring form, attracting or diverting attention. Rather, they clarify and obscure; reveal and conceal at the same time. They might be therefore thought of as "meta-effects", that emerge as the combined result of the range of visual phenomena produced by banded materials.

What Krauss' writings also make clear is that these meta-effects of frontality and rotation also have implications for the observer. As the Watari-um example has demonstrated, frontality implies the orientation of an object towards the viewer, and the positioning of the viewer to meet it. It also suggests that the viewer stands before the object in a fixed position, as one might stand in front of a picture. Furthermore, Krauss argues a frontal view is a contemplative stance that distances the viewing subject - it is ideational and pictorial. It also has a temporal dimension: a frontalised façade compels the viewer to pause, to stand still. In the case of rotation, and as the Watari-um's fire stair and Siena Cathedral both demonstrate, there is no ideal position in which to stand. Rather, the viewing subject is encouraged to move and explore an infinite number of possible views. The experience is phenomenal, haptic and dynamic. The use of stripes to reinforce the directionality of form, affirms that viewers must not only consider their capacity to manipulate perception of that form, but also that they exert a degree of control. The striped façade encourages and anticipates the viewer standing before, or moving about the building, according to its frontal or rotational directives, demonstrating the fundamentally interactive possibilities of striped materials.

This interactivity of frontality and rotation gains even greater potential when the conditions are deployed together. While the two may not be perceived simultaneously - Krauss says it is impossible to see, or to experience, both at the same time (1968: 42) - frontality and rotation can co-exist. This has already been observed in the work of Le Corbusier, and in the Watari-um. Used together, frontality and 
rotation create a theatrical play, made up of spatial tensions, formal contradictions and different temporal rhythms. Importantly, this play can also choreograph movement, and articulate the journey through space with moments of pause, reflection and stillness. This is the essential lesson on frontality and rotation that Krauss identifies in Le Corbusier's work, arguing that: "what Le Corbusier demands of architectural composition is that it should acknowledge the mutual interdependence of the one on the other" (1972: 52).

\section{Stripes, articulation and perceptual artifice}

It is clear, however, that Krauss' interest in frontality and rotation is limited to the formal qualities of Le Corbusier's architecture, rather than the use of ornament - such as stripes - to amplify or reinforce their presence. In conclusion, I would therefore like to move beyond Krauss by speculating on the particular significance of stripes and their capacity to assert (or deny) materiality and directionality. In particular, I would argue that what emerges most strongly from the discussion of striped architecture is ultimately an idea about articulation. By this, I refer to the material and immaterial effects of stripes on architecture that articulate the appearance of form through perceptual interference, and that choreograph movement through space via the assertion and interplay of frontality and rotation.

I would contend that these complex spatial and perceptual effects of stripes constitute a unique kind of ornamental condition. This might be described as "perceptual artifice" - a term with which I am attempting to name the particular type of control that stripes exert over the perception and affective phenomena of architecture. This idea builds upon the two-dimensional illusory principles of stripes, such as the Helmholtz Square illusion, and extends these concepts to the three-dimensional space of architecture. It also exceeds the optical limits of these illusions: perceptual artifice combines an understanding of the visual function of stripes with Krauss' insights on frontality and rotation, to capture their effects on the phenomenal, dynamic and temporal experience of architectural space.

The term, and concept, of perceptual artifice therefore provides us with a new tool that unlocks the possibility of rhetoric concerning the nature of stripes, bridging the gap between existing fields of knowledge in visual art theory and architectural practice. It provides us with the conceptual groundwork upon which we may build a theoretical and practical understanding of the effects of stripes on architectural form, and describe their manifestation of the material and immaterial conditions of architecture between haptic and visual sensation. Perceptual artifice also exposes stripes as an a-semantic device for articulating architecture - a kind of lens through which we perceive, and therefore interact with, space. This is important for the understanding and discussion of the effects of striped buildings, such as the Watari-um, but it is also relevant to much contemporary architecture. In particular, it adds to the lexicon of ideas and concepts of recent decades that are used to describe the material and immaterial conditions of the architectural surface. Indeed, the surface has become a locus of design experimentation and architectural intent for many architects working today.

The idea of perceptual artifice also implies a certain compositional potential for the use of stripes in architecture, through their ability to articulate, punctuate and provide structure to the viewer's experience, movement and sensation. This too has implications beyond the use of stripes, particularly in the context of a resurgent interest in ornament and the typically decorative application of phenomena-producing materials. It also challenges the all-over patterning exhibited 
by much architecture today, which appears to shun compositional control in favour of an unrestrained deployment of sensual materiality and elaborate surface treatments. Moreover, perceptual artifice obliges us to re-examine the use of compositional tools to effect interaction with users. Presently, ideas about interactivity in architecture tend to focus narrowly on technological means, or are substituted for the visual gratification and material pleasure provided by the building surface. Rarely does the architecture of today combine such rich visual and material experiences with the particular spatial effects of frontality, and its unique pleasures of control, articulation and exaggeration.

Perceptual artifice therefore returns us to these all but forgotten ideas for a performative architecture; ideas previously employed so effectively by the likes of Le Corbusier. It is also a timely and important reminder of the inherent and affective power of architecture that lies in the (im)material depths of its surface.

\section{References}

Botta, M. (2012). Interview with Mario Botta / Interviewer: Ashley Paine. [Unpublished]. Botta, M. (1990). Letter to WATARI-UM. In E. Watari (Ed.), Mario Botta: Watari-um Project in Tokyo 1985-1990 (pp. 6-9). Tokyo: Watari-um.

Frampton, K. (1975). Frontality vs. Rotation. In Five Architects : Eisenman, Graves, Gwathmey, Hejduk, Meier (pp. 9-13). New York: Oxford University Press.

Helmholtz, H. v. (Ed.). (1925). Helmholtz's Treatise on Physiological Optics (Vol. III). Birmingham, Alabama: The Optical Society of America.

Krauss, R. (1968). On Frontality. Artforum, 6 (9), 40-46.

Krauss, R. (1972). Leger, Le Corbusier, and Purism. Artforum, 10 (8), 50-53.

Paine, A. (2012). Botta's Striped Historicism: Historicism, Myth and Fabulation in Mario Botta's Stripes. Paper presented at Fabulation: 29th Annual Conference of the Society of Architectural Historians, Australia and New Zealand, Launceston.

Paine, A. (2011). Façades and Stripes: An Account of Striped Façades from Medieval Italian Churches to the Architecture of Mario Botta. Paper presented at Audience: 28th Annual Conference of the Society of Architectural Historians, Australia and New Zealand, Brisbane. Pastoureau, M. (2003). The Devil's Cloth: A History of Stripes (J. Gladding, Trans.). New York: Washington Square Press.

Puttfarken, T. (2000). The Discovery of Pictorial Composition: Theories of Visual Order in Painting 1400-1800. New Haven, Conn.; London: Yale University Press.

Rowe, C. (1996). The Provocative Façade: Frontality and Contrapposto. In A. Caragonne (Ed.), As I was Saying: Recollections and Miscellaneous Essays (pp. 171-203). Cambridge, Mass.: MIT Press.

Sakellaridou, I. (2001). Mario Botta: Architectural Poetics. London: Thames \& Hudson.

Szeemann, H. (1990). A Sounding Triangle. In E. Watari (Ed.), Mario Botta: Watari-um Project in Tokyo 1985-1990 (pp. 37-39). Tokyo: Watari-um.

Van Pelt, J. V. (1902). A Discussion of Composition as Applied to Art. New York: The Macmillan Company.

Watari, E. (Ed.). (1990). Mario Botta: Watari-um Project in Tokyo 1985-1990. Tokyo: Watari-um. Wölfflin, H. (1932). Principles of Art History: The Problem of the Development of Style in Later Art (M. D. Hottinger, Trans.). New York: Henry Holt and Company. 